\title{
A formação continuada de professores para o uso das Tecnologias da Informação e Comunicação (TIC): o caso do projeto Escolas em Rede, da Rede Estadual de Educação de Minas Gerais
}

Teachers continuing formation for the use of Information and Communication Technologies (ICT): the case of Escolas em Rede project, of the public system of Education of Minas Gerais State

Cleder Tadeu Antão da Silva ${ }^{[a]}$, José Ângelo Garíglio ${ }^{[b]}$

[a] Mestre em Educação Tecnológica pelo Centro Federal de Educação Tecnológica de Minas Gerais (CEFET-MG), professor da Universidade do Estado de Minas Gerais (UEMG), Belo Horizonte, MG - Brasil, e-mail: tadeuuemg@yahoo.com.br

[b] Doutor em Educação pela Pontifícia Universidade Católica do Rio de Janeiro (PUC-RJ), professor da Escola de Educação Física da Universidade Federal de Minas Gerais (UFMG), Belo Horizonte, MG - Brasil, e-mail: angelogariglio@hotmail.com

\section{Resumo}

O presente artigo busca discutir as práticas de formação continuada de professores para o uso das tecnologias da informação e comunicação no interior da atual política pública de inclusão digital, implantada pela 
Secretaria de Estado da Educação de Minas Gerais (SEE-MG) - o projeto Escolas em Rede. Nele analisam-se as metodologias de ensino utilizadas nos processos de formação dos professores, assim como os ambientes de aprendizagem e materiais didáticos privilegiados nas ações do programa em questão. Analisa-se, também, o processo de formação dos professores a partir da documentação do projeto daSEE-MG, buscando compreender paralelamente a visão dos professores, formadores e coordenadores envolvidos na proposta de capacitação. O artigo é resultado de uma pesquisa de mestrado de natureza qualitativa, na forma de estudo de caso, com duas turmas de professores que participaram dos processos de formação desenvolvidos pelo projeto de inclusão digital Escolas em Rede, da SEE-MG. A análise dos dados da pesquisa evidencia que a política de inclusão digital da SEE-MG vem sofrendo (d)os mesmos problemas de outras políticas públicas históricas da área, visto necessitar de melhor infraestrutura tecnológica e de pessoal para dar suporte às práticas de uso das TIC nas escolas. Além disso, há ainda um caráter de verticalização na implantação do projeto, considerando que em nenhum momento a política dialoga com a realidade dos professores e de suas escolas de origem, ocasionando um distanciamento entre o programa da SEE-MG e as reais demandas das instituições de ensino e educadores da rede estadual.

Palavras-chave: Políticas públicas. TIC. Formação continuada de professores.

\section{Abstract}

This article seeks to discuss the practices of teachers continuing formation for the use of information and communication technologies inside the present public policy of digital inclusion, implemented by the Department of Education of Minas Gerais State - the Escolas em Rede project. In it, the teaching methodologies used in the processes of teachers' formation are analyzed, as well as the learning environments and the learning materials privileged in the actions of the program. The process of formation of teachers is also analyzed based on SEE-MG project's documentation, aiming to understand, at the same time, the vision of teachers, trainers and coordinators involved in the proposed training. The article is the result of 
a Msc. qualitative research, in the form of a case study, with two classes of teachers who participated of the training processes developed by the project of digital inclusion Escolas em Rede, of SEE-MG. The analyses of the survey data highlights that the policy of digital inclusion of SEE-MG has been suffering of the same problems as other historical public policies in the area, since it needs better technological infrastructure and personnel to give support to the practices of use of the ICT in schools. Furthermore, there is still a vertical implementation of the project, considering that the policy does not relate to the reality of teachers and their schools of origin, at any time, causing a gap between the SEE-MG program and the real demands of the educational institutions and the educators of the State.

Keywords: Public policies. ICT. Teachers continuing formation.

\section{Introdução}

A sociedade contemporânea tem passado por um processo de grandes transformações sociais, políticas, econômicas e culturais. Nesse ambiente, de profundas modificações societais, as chamadas Tecnologias da Informação e Comunicação (TIC) têm presença marcante no conjunto das mudanças anunciadas. No plano econômico, por exemplo, o funcionamento e a organização do sistema capitalista atingiram hoje um estágio em que as TIC têm tido um papel preponderante para o desenvolvimento do setor produtivo, assim como na expansão do setor de serviços. De tal forma, as TIC têm se constituído, portanto, em um instrumento facilitador do cenário globalizado, no qual a informação e o conhecimento são tidos como elementos fundamentais na/para a engrenagem social, se tornando uma marca dos interesses econômicos globais.

Para além da dimensão econômica, o mundo globalizado criou formas novas e singulares de comunicação entre os sujeitos, possibilitando outros modos de interação: as TIC têm permitido outras possibilidades de acesso ao conhecimento e outras possibilidades de relações comunicativas, estreitando o contato entre as pessoas, seja nas atividades de trabalho, seja nas atividades de lazer e/ou entretenimento.

Segundo Belloni (2001), as diversas instituições sociais têm se apropriado e se adaptado às novas demandas que as TIC colocam no atual contexto, o que tem interferido diretamente na vida das pessoas, em sua 
dimensão privada. A nova realidade tecnológica afeta ainda a esfera das competências profissionais exigidas, alterando a configuração do mercado de trabalho e trazendo implicações para os processos de formação dos sujeitos sociais. Essas anunciadas transformações ocorridas afetam também o campo da Educação, exigindo da escola um posicionamento que aponte novos caminhos para os processos de formação, de forma a atender às novas demandas em curso.

Influenciada por esse ambiente, a Educação, e em especial a educação escolar, passa a ser vista como um dos pilares centrais para a expansão do/no uso das TIC. A escola aparece como uma das instituições sociais estratégicas para o enfrentamento desse desafio. Para isso, faz-se necessária a intervenção do Estado, programando políticas públicas com o propósito de democratizar o acesso às TIC nas escolas públicas, visando à utilização adequada dos recursos de ensino com finalidades educativas, como aponta Belloni (2001).

Segundo Pagnez (2006), Correia (2007) e Borges (2007), ${ }^{1}$ tais políticas já vêm sendo implantadas em todo o País, assim como algumas pesquisas que também têm sido realizadas e tentam mapear o campo, discutindo as experiências oriundas dos projetos e programas que visam a integrar as TIC nas instituições de ensino. Diante de tal contexto, tornase essencial destacar, portanto, a importância da formação de professores para o uso das TIC nas escolas: políticas de qualificação voltadas para esses profissionais são estratégias indispensáveis ao projeto de inclusão digital, visto a não formulação de ações nessa direção poder fazer com que as políticas de inclusão digital corram o risco de ficar apenas na dimensão do discursivo político formal, mantendo-se distante da realidade prática das escolas brasileiras, como aponta Farias (2003).

O presente debate constitui o pano de fundo das análises e reflexões que serão desenvolvidas neste texto, que ratifica os resultados finais de uma pesquisa de mestrado ${ }^{2}$ que buscou analisar as práticas de formação continuada de professores da educação básica para o uso das TIC. Assim,

\footnotetext{
${ }^{1}$ Correia (2007) analisa a formação de professores nos cursos de capacitação em informática educativa da Rede Municipal de Educação do Rio de Janeiro. Já Borges (2007) faz uma avaliação da implementação do projeto de inclusão digital do município de Ipatinga, MG. Pagnez (2006) avalia o Projeto Eureka, criado pela Prefeitura Municipal de Campinas, que tem como objetivo introduzir o computador como ferramenta pedagógica para enriquecimento da prática dos professores.
}

${ }^{2}$ Pesquisa financiada e realizada no Programa de Mestrado em Educação Tecnológica do Cefet-MG. 
e mais especificamente, afirma-se que o presente artigo trata dos processos de formação engendrados no interior do projeto Escolas em Rede (ER), da Secretaria Estadual de Minas Gerais (SEE-MG).

\section{A trajetória metodológica}

A pesquisa realizada, e aqui apresentada sob a forma de artigo, pode ser definida como um estudo de caso de cunho qualitativo: o presente trabalho privilegiou a abordagem fenomenológica, que tenta compreender os sentidos e significados que os acontecimentos têm para as pessoas em situações particulares. Buscou-se, assim, entender a realidade específica de um programa de formação continuada de professores, o FIT - Promédio (Formação Inicial para o Trabalho - Programa de Melhoria da Qualidade e Eficiência no Ensino Médio), no interior de um projeto de inclusão digital, de maneira a descrever situações, observar peculiaridades, explicar e compreender comportamentos e posicionamentos dos atores envolvidos. ${ }^{3}$

Para construir uma descrição densa da realidade investigada, lançouse mão de diversas técnicas de coleta de dados: entrevista com professores formadores, professores cursistas e coordenadores do projeto, observação dos ambientes de aprendizagem ou dos momentos de formação, e análise de documentos normativos da política, como o documento oficial do projeto Escolas em Rede, de setembro de 2005, por exemplo. Foram observados ainda o relatório de avaliação da política referente aos anos de 2004, 2005 e 2006, o fluxograma de funcionamento da proposta com a distribuição das ações e responsabilidades dos diversos envolvidos na implantação do programa, e os ofícios de orientação do FIT - Promédio, enviados pela SEE-MG às SRES e às escolas, para direcionamento das práticas de capacitação dos professores. Foram analisados também os materiais didáticos utilizados na formação dos professores por meio do estudo das apostilas de Informática Básica, Editoração Eletrônica e Construção de Websites utilizadas nas práticas de formação dos professores.

Diante de tais estratégias de pesquisa, buscou-se comparar discursos distintos, confrontar posições de diferentes sujeitos sobre o mesmo tema e verificar eventuais contradições entre práticas e discursos.

\footnotetext{
${ }^{3}$ A realização deste estudo de caso possibilitou a verticalização das explicações sobre a realidade investigada e sobre o aprofundamento da análise do objeto de pesquisa.
} 


\section{O caso investigado}

O projeto Escolas em Rede (ER), da SEE-MG, foi criado em 2004, tendo como objetivo principal propiciar às escolas estaduais oportunidades e condições de atuação mais articuladas e cooperativas, por meio da cultura do trabalho em rede e da incorporação das TIC às suas atividades educativas e administrativas.

Atualmente, a formação de professores realizada no projeto é desenvolvida por meio do FIT (Formação Inicial para o Trabalho). Nesta ação da SEE-MG, a capacitação é voltada para os professores do ensino médio, e o foco da qualificação se divide em duas frentes de atuação: a primeira busca oferecer aos professores um treinamento instrumental, para uso das TIC, por meio de vários cursos de informática, de forma que, ao retornar à escola, o docente possa repassar o conhecimento obtido nesses cursos para os alunos, visando à qualificação destes estudantes para o trabalho. A segunda frente objetiva capacitar os professores para o uso dos recursos de informática nas práticas pedagógicas na escola. De acordo com a orientação da SEE-MG, os cursos se colocam como uma ação estratégica do governo estadual para ampliar o uso dos recursos pedagógicos nas escolas, e visam a melhorar a qualidade do ensino e da aprendizagem nas instituições da rede.

A partir de 2008, em nova etapa de implantação, o FIT começou a fazer parte de uma grande ação conjunta entre projeto ER e Promédio, em que os cursos são oferecidos em parceria com o Senac-MG. Várias metas de capacitação foram estabelecidas aos professores como forma de atender à política global do governo de Minas, que privilegia uma gestão voltada para o alcance de resultados. E é neste sentido, de privilegiar o alcance de resultados, que uma clara preocupação surge, visto o foco estar nas metas quantitativas, que sempre buscam o cumprimento de resultados. ${ }^{4}$

\footnotetext{
${ }^{4}$ Para se entender este processo, é preciso compreender também a política global do governo de Minas, que envolve o "choque de gestão". Para Alves (2006), o programa choque de gestão do governo de Minas visa a pôr fim à crise fiscal e administrativa herdada das gestões anteriores. Seu objetivo é "reformar o Estado, obter saldo positivo entre arrecadação e despesas - denominado 'Déficit Zero', monitorar ações para que se obtenha o máximo de eficiência nas intervenções do governo e resultados positivos. As ações implementadas nesse sentido buscam revisar o modelo de gestão dos recursos humanos, dos processos e rotinas administrativas, consolidar a parceria com o terceiro setor e o setor privado na prestação do serviço público, alinhadas à avaliação de desempenho institucional e individual e à transparência da ação pública” (ALVES, 2006, p. 3). É parte desta política o "acordo de resultados", que é um pacto firmado entre o governo de Minas e os órgãos do Estado visando ao alcance de metas previstas no caderno de desafios e prioridades constantes no Plano Plurianual de Ação Governamental (PPAG). O PPAG é o planejamento estratégico do Estado a ser desenvolvido no período de quatro anos.
}

Rev. Diálogo Educ., Curitiba, v. 10, n. 31, p. 481-503, set./dez. 2010 
Assim, são oferecidos pela SEE-MG, em parceria com o SenacMG, 11 cursos de capacitação em informática básica para os professores da rede, sendo que os softwares escolhidos pelo FIT - Promédio privilegiam a dimensão profissional de preparação para o trabalho, disponibilizando aplicativos que atendem diferentes nichos de mercado. ${ }^{5}$ Os cursos de capacitação apresentam carga horária que varia de 40 a 80 horas, e, ao fim do processo de formação, é oferecida certificação aos docentes mediante a comprovação da divisão dos conhecimentos aprendidos nos cursos com os alunos da Rede.

\section{Formação continuada dos professores ou profissionalização dos estudantes para o trabalho?}

O modelo de formação praticado pelo FIT - Promédio demonstra, na prática, que existe na realidade uma espécie de dispersão de objetivos e, de certa forma, uma sobrecarga de suas finalidades. Uma única política pretende, ao mesmo tempo, atingir dois propósitos distintos de formação: de um lado, busca-se preparar os jovens matriculados no ensino médio para o trabalho, procurando oferecer-lhes mecanismos de inserção profissional. De outro, objetiva-se formar os professores da rede estadual para utilizar as TIC em suas atividades pedagógicas nas escolas, como mostra o depoimento ${ }^{6}$ a seguir:

o que foi passado é que os professores fariam um curso básico, não é? Não era exigido nenhum pré-requisito pra isso. O objetivo era que quando eles voltassem para as escolas, eles multiplicassem para os alunos do ensino médio e ao mesmo tempo pudessem fazer uso disso nas suas turmas, não é? Como estava aberto para todos os professores, ele multiplicaria para alunos, mas também poderia usar na sua aula. O professor de Biologia, ele poderia usar também nas aulas de Biologia, mas o seu compromisso era multiplicar para os alunos do ensino médio (SS04F).

\footnotetext{
${ }^{5}$ Os cursos oferecidos são de Linux, Blender, Impress, Introdução de Banco de Dados, Qcad, Gimp, Open Office Calc e Open Office Writer, com carga horária de 40 horas. O curso de Editoração Eletrônica é o único com carga horária de 60 horas, e os cursos de Montagem e Manutenção de Computadores e Construção de Websites apresentam carga horária de 80 horas. No caso do curso de montagem e manutenção de computadores, as escolas devem possuir laboratórios específicos para realização do curso em questão.

${ }^{6}$ Foi adotada uma sigla para representar os autores de todos os depoimentos que serão apresentados como citação direta. Ressalta-se ainda a transcrição literal do que foi dito pelos entrevistados.
} 
A citada dispersão de objetivos tem dificultado ou mesmo impedido que os objetivos propostos na concepção do projeto sejam alcançados. Para se ter uma ideia do fracasso dessa política de formação continuada de professores para o uso das TIC, basta acessar o que tem sido o seu resultado prático. Como exemplo, pode-se citar o que foi encontrado durante a pesquisa realizada: entre os 18 professores entrevistados, apenas dois, cerca de $11 \%$ do total da amostra, têm conseguido realizar o repasse dos cursos aos alunos nas escolas.

A Tabela 1 mostra o panorama de repasse dos cursos entre os professores participantes da formação entrevistados.

Tabela 1 - Professores que realizaram repasse dos cursos nas escolas pesquisadas (FIT - Promédio - 2009)

\begin{tabular}{lllll}
\hline Cursos & $\begin{array}{l}\text { Carga } \\
\text { horária }\end{array}$ & $\begin{array}{l}\text { Cursos } \\
\text { multiplicados }\end{array}$ & $\begin{array}{l}\text { Cursos não } \\
\text { multiplicados }\end{array}$ & Total \\
\hline Editoração Eletrônica & 60 horas & 00 & 10 & 10 \\
Construção de Websites & 80 horas & 02 & 06 & 08 \\
\hline
\end{tabular}

Fonte: Dados de pesquisa efetuada em 2009.

No que diz respeito a um dos objetivos centrais do FIT Promédio, o de qualificar profissionalmente os alunos do ensino médio, o projeto acaba reduzindo a educação profissional a um mero treinamento. Como qualificar alguém para o mundo do trabalho com uma formação restrita de 40, 60 ou 80 horas? $?^{7}$ Qual qualidade pode ser constatada nessa formação, se os professores que profissionalizam os alunos (os professores do ensino médio cursistas do FIT - Promédio) são tomados como meros instrutores ou repassadores de conteúdos tecnológicos que não dominam ou desconhecem? Que formação profissional é essa já que a integração entre os conhecimentos tecnológicos e os conhecimentos da educação básica não é considerada?

A concepção de formação profissional expressa na política eleita

\footnotetext{
${ }^{7} \mathrm{O}$ curso técnico de informática oferecido pelo Senac-MG apresenta carga horária de 1.000 horas. Já os cursos de capacitação em softwares similares aos oferecidos pelo FIT-Promédio variam entre 15 e 75 horas, mas apresentam pré-requisitos de formação mediante os testes de conhecimento específico, o que não ocorre na proposta da SEE-MG. Os cursos oferecidos aos professores da rede estadual não constam como abertos ao público em geral.
} 
pelo governo de Minas Gerais, em especial, entende a educação profissional como simples transmissão de conteúdos técnicos operacionais de um determinado ofício. Essa visão estreita é diametralmente oposta a uma perspectiva teórica mais crítica, e que entenda a educação profissional como ensino e aprendizagem de conteúdos, de métodos e de relações necessárias à compreensão, à pesquisa e à aplicação crítica e criativa das bases científicas nos processos e procedimentos científicos.

Pode-se constatar, assim, que a opção feita para capacitar os professores dentro de um modelo que apresenta carga horária limitada não possibilita uma articulação efetiva da tecnologia enquanto ferramenta de mediação didática, fato comentado pelos docentes, como se observa nos depoimentos a seguir:

o curso é intenso para pouco tempo e impossivel de ser repassado para os alunos, justamente porque um professor que far. graduação de quatro anos daquilo passa pra gente em uma semana, pra depois a gente conseguir passar isso para o aluno... O ponto negativo que eu vejo é esse, muito conteúdo para pouco tempo. A formação, por mais que o professor lá tenha tido capacidade de passar pra gente as informações, o que era básico que a gente precisava saber, colocar em prática, em tão pouco tempo não deu. Colocar em prática não dá tempo e muito menos ensinar outra pessoa (PC02F).

um pouco complexo que precisaria um pouquinho mais de tempo, um pouquinho mais de trabalho da gente, conhecimento próprio mesmo, porque fica difícil a gente repassar para os alunos. Porque a gente via que até o professor mesmo tinha um pouco de dificuldade em determinadas partes pra poder passar (PC02F).

No tocante à formação continuada dos professores para o uso pedagógico das TIC, pôde-se observar que as práticas pedagógicas de formação, realizadas pelo FIT - Promédio, pouco dialogam com a realidade do trabalho dos professores na escola. Ao terceirizar a formação continuada dos docentes via contrato com o Senac-MG, o que a SEE-MG faz é reproduzir, quase que na totalidade, um modelo de qualificação ou capacitação profissional já constituído por essa entidade, e que privilegia a instrumentação de habilidades de informática básica.

De acordo com Nascimento (1997), é preciso questionar esses modelos de formação de professores, que são pensados dentro da lógica da racionalidade científica e técnica, privilegiando a transmissão de saberes. Para a 
autora, há uma constatação da falência destas estratégias, pois são concebidas como pacotes prontos, estabelecendo distância com a realidade escolar. Ainda segundo Nascimento (1997), esses modelos são práticas privilegiadas pelo Estado na divulgação de novos métodos e orientações, com forte caráter prescritivo e que privilegia um viés de reciclagem como meio de divulgação de políticas.

Nascimento (1997) complementa o seu pensamento afirmando que os modelos de formação continuada ainda demonstram desinteresse pela valorização do conhecimento dos professores, não lhes dando voz na formulação das políticas. Além do mais, nunca são divulgadas as experiências bem-sucedidas realizadas pelos docentes, importando-se muitas vezes outros modelos do exterior, que não representam questões reais da prática dos educadores, o que compromete o sucesso das estratégias adotadas pelos sistemas de ensino e pelas administrações educacionais.

Nesse sentido, todo o direcionamento da proposta do FIT Promédio se concentra em preparar os professores para que estes atuem como multiplicadores dos cursos oferecidos pelo Senac-MG nas escolas estaduais, confirmando que a preocupação central está focada na iniciação dos estudantes do ensino médio no mercado de trabalho, ação esta voltada para uma educação profissionalizante somente, como se observa:

o FIT, ele entrou com uma ação dessa (Promédio), não sópra ser um atrativo para o aluno permanecer na escola, porque para participar o aluno tem que estar regularmente matriculado na escola, mas também dando condições pra ele no mercado de trabalho. E hoje a informática, ela é fundamental... Não se trabalha mais sem informática, é muito difícil ter um trabalho que não envolva informática, então o aluno já sai com um diferencial (AE03M).

A contratação de uma agência externa, com pouca experiência no campo da formação docente, corrobora com a escolha da política educacional eleita pelo governo mineiro. A escolha do Senac-MG não se deu somente pela sua relevância social enquanto agência apta para atuar no campo da formação de professores, mas sim pelo reconhecimento do trabalho realizado por esta entidade no campo da educação profissional.

Gatti (2008), por exemplo, ao discutir a respeito da multiplicação da oferta da educação continuada, afirma que uma das preocupações centrais dos administradores públicos tem sido exatamente a escolha de instituições reconhecidas para auxiliar o poder público na implementação das propostas de formação contínua, fator que se torna fundamental para este processo. 
com a multiplicação da oferta de propostas de educação continuada, apareceram preocupações quanto à "criteriosidade", validade e eficácia desses cursos, nas discussões da área educacional em geral, nas falas de gestores públicos da educação, em instituições da sociedade civil financiadoras de iniciativas dessa natureza e nas discussões e iniciativas dos legisladores. Essa preocupação apresentou-se, por exemplo, em alguns administradores públicos, que em seu campo de atuação implementaram, ou encontraram em implementação, programas de educação continuada para professores ou outros segmentos escolares. Alguns desses administradores já vinham tomando medidas para tentar garantir certa qualidade a esses programas na seara pública, com estabelecimento de critérios, em editais e resoluções executivas, para as instituições que se responsabilizariam pelos trabalhos, investindo nas mais credenciadas, com financiamento de avaliações externas para acompanhamento das ações formativas nessa modalidade ou estruturando essas iniciativas com seus próprios quadros. Assim, encontramos universidades bem qualificadas e instituições com tradição de qualidade envolvidas nesses projetos em associação com o MEC e com Secretarias de Educação estaduais ou municipais [...] (GATTI, 2008, p. 60-61).

No caso do FIT - Promédio, a escolha da instituição parceira não considerou a dimensão da formação continuada dos professores, girando em torno apenas dos objetivos relacionados à capacitação dos estudantes de ensino médio, apesar dos cursos serem formatados e ofertados para/ aos educadores da rede estadual de ensino.

Outro problema identificado pelos professores no processo de integração das TIC às práticas pedagógicas está na distância entre o processo de capacitação e a realidade escolar. No que diz respeito ao trabalho dos professores, as ações privilegiadas nos cursos oferecidos pelo Senac-MG não trazem orientações claras sobre o uso das TIC e a sua relação com as finalidades didáticas próprias do trabalho dos professores na escola. Não se coloca em relevo questões que são fundamentais aos processos de formação que visam a integrar as TIC à prática pedagógica dos professores. Dentre várias questões, duas, de relevância fundamental, são citadas: a especificidade do lócus escolar e a aprendizagem de didáticas específicas ao uso das TIC no ambiente de ensino. 
Deve-se dizer ainda que a sinalização de preocupação com a realidade escolar já é uma discussão antiga na literatura da formação de professores. Candau (1997), por exemplo, trata das propostas mais atuais da formação continuada de docentes, afirmando que o lócus desta formação deve ser a própria escola. Para a autora, a instituição escolar é o espaço adequado para o professor articular os componentes formativos aos aspectos relacionados ao seu cotidiano, promovendo processos coletivos de reflexão, sistematizando suas práticas pedagógicas e as socializando com seus colegas. Com isso, e ainda segundo Candau (2007), se tornaria possível iniciar, a partir de necessidades reais da prática, a promoção da pesquisa-ação, tendo como referência fundamental o saber docente.

Trata-se de trabalhar com o corpo docente de uma determinada instituição, favorecendo processos coletivos de reflexão e intervenção na prática pedagógica concreta, de oferecer espaços e tempos institucionalizados nesta perspectiva, de criar sistemas de incentivo à sistematização das práticas pedagógicas dos professores e à sua socialização, de ressituar o trabalho de supervisão/orientação pedagógica nessa perspectiva. Parte-se das necessidades reais dos professores, dos problemas do seu dia a dia e favorece-se processos de pesquisa - ação (CANDAU, 1997, p. 58).

A desconexão observada entre o FIT - Promédio e a realidade concreta do trabalho dos professores na escola pode ser analisada quando se compara a infraestrutura disponibilizada pelo Senac-MG (laboratórios de informática, computadores, softwares, recurso multimídia) e aquela encontrada pelos docentes em suas escolas, da rede estadual. Valente (1998), que discute, desde a década de 90, algumas práticas de formação de professores para o uso das TIC, explica o porquê da importância do contexto da escola como um dos elementos fundamentais na formação docente para uso dos recursos tecnológicos em sala de aula. Para o autor, uma abordagem construcionista para uso das TIC na escola favorece uma prática pedagógica mais reflexiva na relação com o conhecimento, e, sendo assim, e ainda para o autor, os processos de capacitação deveriam ocorrer, portanto, preferencialmente no espaço escolar. Para Valente (1998), a familiaridade do professor com o ambiente e com os recursos de seu local de trabalho contribuem significativamente com a sua aprendizagem e em sua relação com as tecnologias. 
Um curso de formação baseado na abordagem construcionista para ser efetivo deve ser desenvolvido na escola, onde o professor trabalha. Isso apresenta diversas vantagens tanto para os professores como para o professor do curso. Primeiro, o conhecimento adquirido é contextualizado. A familiaridade dos professores com o computador acontece através do uso do computador da escola, com o sistema computacional e com a rede de computadores montada na escola. A experiência de aprender e de usar o computador acontece na escola, utilizando a população da escola, como meio dos professores exercitarem e construírem o conhecimento sobre a informática na educação. Segundo, os professores não deixam seu local de trabalho e não têm que interromper a sua prática de ensino. As atividades do curso de formação podem ser organizadas de acordo com os horários dos professores. Terceiro, o professor do curso pode ser mais efetivo. Ele pode vivenciar e entender as idiossincrasias daquela escola de modo que as soluções pedagógicas e administrativas podem ser baseadas na realidade da comunidade escolar. Os professores e a administração da escola, através dessa vivência, vão adquirindo conhecimento sobre como implantar a informática como recurso pedagógico na escola (VALENTE, 1998, p. 6-7).

No caso do FIT, a falta de suporte técnico presente nas escolas (profissional habilitado ao acompanhamento das práticas pedagógicas e de manutenção dos laboratórios) e as dificuldades impostas pela precariedade dos equipamentos de informática comprometem diretamente o processo de integração das TIC nas ações didáticas conduzidas pelos educadores, deficiências que estão em desacordo com o que propõe Kenski (2003) em relação à importância de uma boa infraestrutura tecnológica para as escolas. Segundo a autora, tal estrutura mostra-se como fator imprescindível na implantação de projetos desta natureza.

A resolução destas questões estruturais - existência de equipamentos adequados e suficientes e a garantia de acesso às facilidades e aos serviços tecnológicos mais recentes e abrangentes - recai diretamente a uma série de outras decisões sobre o modelo de educação tecnológica que a instituição de ensino vai poder oferecer aos seus alunos. [...] Questões como: qual é o propósito da escola - ensinar os alunos a lidar com o computador e a internet ou ensinar com o computador? A resposta a essa primeira indagação orienta a tomada de decisão para novas questões: que tipo de equipamento adquirir? Em que quantidade? Para que usos? Quem vai poder utilizar estes 
equipamentos? Quando e como serão disponibilizados? Em que espaços vão estar localizados? Que tipo de apoios, técnicos e pedagógicos, estarão disponíveis? Mais ainda: como serão realizadas a manutenção dos equipamentos e assistência técnica? (KENSKI, 2003, p. 72).

Neste sentido, Kenski (2003) destaca que alguns fatores devem ser valorizados na construção de boas propostas para o uso destas tecnologias nas escolas. Entre os fatores destacados pela autora está justamente a existência de uma boa infraestrutura tecnológica, que se coloca como um elemento importante para o sucesso da implantação dessas políticas. Nas palavras da autora, "assumir o uso das tecnologias digitais no ensino pelas escolas, requer que ela esteja preparada para realizar investimentos consideráveis em equipamentos e, sobretudo, na viabilização das condições de acesso e de uso dessas máquinas" (KENSKI, 2003, p. 70).

Sob o ponto de vista da interlocução estabelecida entre a política do FIT - Promédio e os professores, os dados demonstram que os docentes desconhecem qualquer tipo de diálogo estabelecido entre a SEE-MG e a escola, ou mesmo com os próprios professores. Em nenhum momento os docentes foram chamados a opinar ou a participar da construção da proposta do FIT, o que sinaliza que o processo de implantação dessa política de formação foi de certa forma imposta e ausente de diálogo com as demandas das escolas e de seus professores.

Os docentes pedem para que as políticas públicas observem as verdadeiras necessidades e demandas das escolas, de maneira a melhorar a comunicação e a interação entre os atores envolvidos, fator que não ocorre nos projetos da SEE-MG, como mostram os relatos de alguns professores:

primeiramente, antes de formar, fazer esse projeto, olhar ao redor e ver a necessidade. Uma escola não é igual à outra, uma escola precisa de um recurso, a outra de outro. Partir do pressuposto que existem profissionais diferentes, montar turmas homogêneas. A partir desse olhar, montar as turmas e dar o suporte para o professor. Seria um ponto crucial para dar certo. Olhar mais para a escola em primeiro lugar, depois na hora de montar as turmas dar um suporte para esse professor continuar multiplicando (PC02F). olha, a Secretaria é uma coisa complicada, porque eles tomam as decisões lá em cima, não conbeço e não conbeci nenhum professor até hoje que tenha sido ouvido. Um professor assim... O que eles ouvem lá são os professores que estão dentro de uma universidade e que ficam trancados nos gabinetes 
deles, tá? Não ouvi até hoje, mesmo quando eu era aluna da UFMG, um professor que trabalhasse, por exemplo, aqui no bairro Santa Mônica, no Palmital, lá em Santa Lu₹ia, um professor que estivesse numa escola estadual, dentro duma sala de aula. É sempre um professor que está dentro de um gabinete, que é uma coisa que a gente reclama muito. Por quêe? Ab! Entre aspas, o mundo deles é colorido, porque os alunos da universidade, você sabe que é de outro nivel, não tem nada a ver com os alunos da escola estadual. Você concorda comigo, não concorda? (PC02F).

só iria contribuir se quem é responsável por gerenciar as demandas de uma escola tivesse esse choque de realidade que nós professores temos. [...] Então quem organiza isso, quem pensa nessa formação continuada para os professores, deveria também ter esse choque de realidade que a gente tem, tanto deles lá com tudo disponivel e à mão pra eles e chegar nas escolas e deparar com o que a gente vê, com a falta de recursos que a gente tem na escola (PC02F).

Não obstante o reconhecimento das fragilidades da formação propiciada pelo FIT - Promédio, é importante citar também que os professores, em seus depoimentos, reconhecem a iniciativa da SEE-MG como válida. Para eles, o espaço de formação propiciado pelo FIT - Promédio é positivo, já que possibilita uma capacitação em serviço e uma aproximação com alguns dos instrumentos disponibilizados pela informática. Esta aproximação se materializa na abertura de novas possibilidades didáticas, estando, entre elas, a ampliação das fontes de pesquisa e outras formas de avaliações das atividades de ensino.

A abertura de novas possibilidades, no entanto, se materializa na atividade docente apenas em relação ao planejamento pedagógico, nos momentos de estudo, pesquisa e construção de planos e atividades para os alunos, dando uma nova visão de uso das tecnologias para os educadores no âmbito de sua atuação como professores. De tal forma, a contribuição do FIT - Promédio se localiza, segundo os docentes, nas melhorias obtidas na confecção de avaliações, na utilização de novas formas de pesquisa na internet e nas alterações realizadas no momento de concepção das aulas e outras práticas, como a elaboração de tarefas, atividades e exercícios.

Todavia, os dados da presente pesquisa mostraram que são poucos os docentes que têm conseguido integrar as TIC no fazer didático diário. Aqueles que relataram ter conseguido essa integração são exatamente os docentes já iniciados no universo da informática, com experiências e formação anteriores à chegada ao FIT - Promédio. Apenas uma professora, dentro 
do universo da pesquisa, tem realizado um trabalho mais ativo na utilização das TIC em sala, como se observa em seu depoimento:

Você não tem nem ideia como foi excelente. Estimulou tanto que comprei um notebook. As minhas aulas agora são no Power Point. Porque a proposta é da gente estar criando na escola com os alunos. [...] Somos a ponte de coordenar um grupo de alunos que vai trabalhar fazendo páginas da internet. Isso estimula os alunos, o que eles vão criar vai ser divulgado para a escola toda e com isso eu estou inserindo mais eles na tecnologia. Os meus trabalhos todos en estou pedindo para eles fazerem em grupo assim, de alunos que não têm computador com alunos que têm computador, todos os grupos de trabalho, todos os mens trabalhos eu estou pedindo para eles fazerem ou CD ou pendrive. Ai eles fazem para mim e me mandam por e-mail antecipado, não é? Ai eu trago o notebook e em casa eu dou uma olhadinha, faço as minhas avaliações, entendeu? Aqui na escola eu passo para eles. Repasso para eles. Eles mesmos fazem os trabalhos. Eles trazem ou em pendrive ou em disquete ou em CD e me passam. Ou mandam por e-mail. Depende de cada um, porque aluno que não tem computador não tem como, mas alguém no grupo dá um jeitinho, entendeu? Eles mandam por e-mail, eu avalio o trabalbo deles, não é? Faço a minha avaliação, faço alguns consertos, entendeu? E marco o dia deles estarem repassando na sala através do notebook $e$ data show. Está vendo como estou estimulada? Eu sei da dificuldade por ser escola estadual, tem aqueles não é? Aqueles negativos. É bobagem! Aqui é escola estadual! Eu sei que tem as resistências, não é? Mas eu não preocupo não, eu estou avançando, no meu jeito. Minhas aulas agora são aulas de primeiro mundo! (PC04F).

O relato desta professora demonstra que fazer um trabalho intenso com as TIC em sala, utilizando projeção multimídia e incentivando os alunos a trabalhar com as tecnologias, acrescenta em seu histórico, como profissional, uma experiência formativa que justifica esta prática diferenciada na comparação com a de outros docentes.

O estímulo criado a partir dos cursos do FIT, de certa forma, se explica pelo envolvimento que a professora já tinha com a tecnologia, inclusive com a participação anterior em outra política pública do campo da inclusão de TIC na escola, como pode se observar em outro depoimento:

os conteúdos que foram desenvolvidos lá, realmente eu não tinha a perspectiva que eu tenho boje, entendeu? Agora o fato de trabalhar com tecnologia, isso bá bastante tempo en já vinha mexendo. Inclusive na outra escola eu fazia tratamento nas cordas vocais e eu fiquei dois anos fora de sala de aula. Ai a direção me 
colocou na sala de informática, que eu desenvolvia trabalho com os alunos, dentro da sala de informática. Com pouco recurso a gente fazia adaptação, remontava aqueles computadores que estavam ultrapassados e fazia trabalhinhos assim de informática. [...] Já tinha por causa do Proinfo, não é? O Proinfo já tinha me dado essa abertura como trabalhar, por exemplo, uma sala com 40 alunos com dez computadores? Na maior parte da escola estadual os computadores são todos ultrapassados, falta muita peça. A insegurança da maioria das direções é porque não pode mexer, porque o computador vai estragar e é aquela coisa. São empecilhos, não é? Isso tudo sendo impedimento não atrapalhou pra mim. Eu fui adiante nesse ponto aí, e os próprios alunos ajudavam mesmo a trabalhar na sala de informática. Fazia um termo de compromisso, eles traziam peças de casa, ajudavam a montar. Então eu já tinha essa experiência com informática, entendeu? Não foi assim tão surpresa pra mim, não (PC04F).

Os dados evidenciam que, além desta professora com experiência anterior na área, apenas outro educador, num universo de 18 entrevistados, progrediu na integração das TIC em suas atividades de ensino. Este professor tem conseguido fazer maior uso das TIC com seus alunos, já que construiu um website para suas turmas interagirem, seja baixando arquivos e acessando textos, seja trabalhando com outras ferramentas tecnológicas. Entretanto, este educador também tem em seu histórico de formação um diferencial para ter alcançado um trabalho voltado para o uso das tecnologias na escola. Seu depoimento mostra que o fato de ter cursado durante algum tempo uma graduação na área tecnológica facilitou significativamente a sua capacidade de promover práticas de utilização das tecnologias.

Pra mim foi muito bom, en gosto, e a minha primeira opscão foi informática - eu fui pra matemática por acidente. Já gostava antes de entrar na faculdade. Já dominava muito a informática, depois que eu entrei pra faculdade eu larguei. Tive uma época de pavor com a computaşão, não sei por quê. Eu acho que era mais porque era meu sonho mesmo seguir aquilo e eu não fui, não é? (PC02M).

A bagagem anteriormente adquirida favorece, assim, um aproveitamento melhor das aprendizagens oferecidas pelo curso do SenacMG e uma apropriação/integração mais qualificada dos recursos didáticos propiciados pelos recursos das TIC. Entretanto, alguns professores questionam sua própria participação nessa política da SEE-MG, já que estão sendo preparados para exercer uma função para a qual não foram formados, e sim treinados dentro de um formato que vem demonstrando não ser o mais adequado para desenvolver a inclusão digital nas escolas da rede estadual. 
Eu gostei porque é uma área que en gosto... Agora um profissional de informática vê que alguém em outra área esta recebendo aquela formação pra repassar isso numa escola, bem... É uma coisa que um novo professorpoderia ser chamado pra isso... E que formou pra isso... Então, assim, é a mesma coisa que uma pessoa que fez Pedagogia vai fazer um curso que o Estado dá aí, de alguns meses, e vai pra sala de aula dar Matemática... Que eu que cursei Matemática durante anos, se eu visse aquilo eu vou falar: poxa, tem mão de obra sobrando aqui e tão dando um jeitinho para aquelas pessoas que estão aí assumirem esse papel... Então assim eu acho complicado nesse sentido (PC02M).

Eu falaria que o Senac seria o mundo adequado para o Estado estar aplicando nas escolas dele. Um aluno por computador, entendeu? Professor especializado naquilo, entendeu? Por que na realidade ele esta usando a gente como um quebra-galho. Eu acho assim, porque em uma semana a gente não vira especialista! O problema é esse! Assim, o Estado estar pagando para gente fazer um curso para melhorar nossas aulas, melhorar nossas estratégias dentro de sala. Maravilhoso! Agora, repassar... Com o objetivo de repassar? Qual que é o objetivo deles? E nós, professores? A gente não teria que estar aprendendo para estar melhorando dentro de sala? Pra estar aplicando as estratégias dentro de sala? Por que pensar só no aluno? Por que não pensar no professor? Não está escrito lá no plano de carreira que o professor tem que fazer a formação continuada? E aí? Esses cursos não entrariam na formação continuada? (PC02F).

Neste aspecto, Melo (1999), ao discutir os programas oficiais de formação docente, afirma que o movimento pela formação de professores em exercício, a partir da nova LDB 9.394/96, estimulou os chamados programas de aperfeiçoamento em serviço. Para ela, a disseminação destes programas impulsionou o formato do treinamento, que tem ocupado o lugar de uma formação mais abrangente, crítica e reflexiva.

Parece haver uma redução na concepção de formação docente, de modo a colocá-la tão somente no âmbito da capacitação. Ou seja, os instrumentos, mecanismos e conteúdos escolhidos pretendem se voltar, fragmentariamente, para um dos aspectos da formação docente, que é como podemos considerar a capacitação em serviço. Esse excesso de pragmatismo tem contribuído para que se confunda o espaço e as finalidades de cada um desses elementos e, mais que isso, tem restringido o direito a uma política de formação ampla, permanente e contemporânea, em troca de aligeirados e modulares momentos de aperfeiçoamento (MELO, 1999, p. 53).

Sendo assim, observou-se que o impacto da formação oferecida pelo FIT - Promédio no processo de incorporação das TIC às práticas 
pedagógicas dos professores foi bastante tímido. Isso porque a sua política tem se caracterizado por oferecer uma capacitação em serviço de curta duração em detrimento de uma concepção sólida, consistente e permanente de formação continuada. Ao eleger tal posicionamento, constata-se que a formação pedagógica torna-se submissa diante da Educação Profissional e a lógica interna das TIC, apresentando-se como um objeto e um objetivo marginal à proposta inicialmente feita.

\section{Considerações finais}

A análise dos dados da pesquisa realizada evidencia que a política de inclusão digital da SEE-MG sofre dos mesmos problemas de outras políticas públicas históricas da área. Um desses problemas restringe-se ao princípio ordenador a elas inerente, que é autoritário na medida em que trata escolas e professores como meros aplicadores de técnicas operacionais das quais não são autores. Esta verticalização do processo de implantação do projeto impõe o silencio e o monólogo, produzindo com isso um abismo entre o que se propõe e as reais demandas das instituições de ensino e educadores da rede estadual. É a crônica da morte anunciada: o projeto consubstancia-se em estrondoso fracasso.

Ao enfatizar conhecimentos/práticas técnico-instrumentais de uso das tecnologias, com vistas à qualificação dos estudantes de ensino médio para o mundo do trabalho, o trato com a dimensão pedagógica da formação dos docentes acaba por ficar em um segundo ou terceiro plano. Tão grave quanto isso é a concepção de profissionalização dos estudantes embutida no projeto FIT - Promédio. Ao tratar a educação profissional como treinamento aligeirado, em detrimento de uma formação tecnológica sólida, o referido projeto acaba não fazendo bem nem uma coisa nem outra. Não profissionaliza os estudantes, nem contribui com formação continuada dos professores.

Os dados levantados pelo presente artigo apontam para a necessidade de se pensar em outro ou outros modelos de/para a formação de professores. Este estudo revela que a integração das TIC às práticas pedagógicas é investimento complexo e que requer dos professores o desenvolvimento de habilidades e a aquisição de conhecimentos não menos complexos. Tal realidade implica a produção de políticas de formação mais perenes e a produção de programas de longo prazo, que respeitem os diferentes níveis de iniciação dos docentes diante do universo da informática e dos recursos audiovisuais. 
Vosgerau et al. (2010), por exemplo, ao discutir variados modelos de integração dos recursos tecnológicos pelos professores nas escolas, afirma que os processos de integração não devem se restringir apenas ao trabalho pedagógico realizado pelos professores nas atividades de ensino. Segundo a autora, discutire avaliar a integração das tecnologias em ambientes escolares deve considerar outros aspectos relacionados à gestão pedagógica destas instituições, assim como outras questões relacionadas ao uso que os alunos e gestores fazem das tecnologias e das possibilidades oferecidas pela instituição escolar no processo de inclusão digital das comunidades.

Vosgerau et al. (2010) afirma que, considerando a complexidade da escola, tais elementos se colocam como fatores que não podem serignorados na construção de um modelo brasileiro para a integração das tecnologias nas práticas pedagógicas, sendo estes elementos fundamentalmente necessários para orientar os programas de formação continuada de docentes para uso pedagógico das tecnologias nos espaços educativos.

Pode-se verificar, diante do quadro exposto, portanto, que as políticas de formação necessitam dialogar com as demandas e com as necessidades reais das escolas, o que implica ação qualificadora do Estado diante das condições de infraestrutura da escola pública. Não há política de formação que dê conta de resolver questões de ordem estrutural, como a falta de apoio técnico nas escolas, laboratórios de informática obsoletos ou depredados, dentre outros obstáculos dessa natureza.

No caso da formação inicial, torna-se imprescindível que as TIC se tornem uma realidade nos currículos das licenciaturas. As Diretrizes Curriculares Nacionais para a Formação de Professores da Educação Básica instituem, entre suas orientações, exatamente "o uso de tecnologias da informação e da comunicação e de metodologias, estratégias e materiais de apoio inovadores" (BRASIL, 2002, p. 1), de forma a favorecer a melhoria da atividade dos professores destes níveis de ensino. Stahl (1997) já sugeria a inclusão de disciplinas específicas nos cursos de formação inicial para a utilização das tecnologias em ambientes escolares pelos futuros professores, como se observa nas palavras da autora:

as possibilidades para se propiciar aos professores o desenvolvimento de habilidades no uso das novas tecnologias podem variar bastante. A inclusão de uma disciplina específica nos cursos de formação de professores parece ser o caminho para que todos os futuros professores cheguem às escolas dominando certas habilidades (STAHL, 1997, p. 312). 
Para Brighenti e Barros (2004), as mudanças ocasionadas pela presença da tecnologia na sociedade atual não só justificam, mas exigem uma rediscussão da formação inicial dos professores, na qual se deve repensar a estrutura dos cursos, assim como seus conteúdos e metodologias atuais.

Essa análise sobre as modificações atuais que interagem entre si são essenciais à compreensão da importância do trabalho educativo na formação de professores. Para tanto, questionamos: como não integrar as tecnologias e não ressignificar os paradigmas do processo ensino-aprendizagem se a própria condição humana está sendo influenciada na sua amplitude pelas tecnologias e suas possibilidades? É importante salientar que as mudanças não podem ser superficiais. É preciso rever os diferentes aspectos que interferem na formação desse profissional, definindo e reestruturando seus cursos, no que tange ao tratamento dos conteúdos desenvolvidos e às ações realizadas durante a formação do futuro professor (BRIGHENTI; BARROS, 2004, p. 133-134).

O movimento da formação inicial não pode estar, entretanto, desvinculado da formação continuada e em serviço, especialmente quando se fala das tecnologias da informação e comunicação que estão constantemente em evolução na sociedade atual. $\mathrm{O}$ investimento na formação continuada de professores, no interior das políticas de inclusão das TIC nas escolas, representa o fortalecimento da esfera da educação continuada para que os professores se tornem sujeitos ativos e participantes das transformações que se busca implementar por meio da utilização dos novos recursos pedagógicos.

Ao se considerar a importância das TIC nas escolas, as ações desenvolvidas na formação inicial e continuada dos professores, numa sociedade em que a inclusão digital passar a ser vista como ponto estratégico ao desenvolvimento da sociedade, podem colocar a profissão docente e a escola em outro patamar de importância sociocultural. Sob esta perspectiva, os professores podem se tornar sujeitos estratégicos ao processo de construção de novas possibilidades de pensar e agir o mundo.

As constatações apresentadas fazem crescer ainda mais a importância de se repensar as políticas educacionais que tratam da formação de professores para uso das TIC, de forma que estas deixem o plano das possibilidades vislumbradas e caminhem em direção à utilização concreta destas tecnologias como recursos de auxílio às práticas dos professores, como costuma constar nos objetivos formais destas políticas do campo. 


\section{Referências}

ALVES, A. C. T. As reformas em Minas Gerais: choque de gestão, avaliação de desempenho e alterações no trabalho docente. In: SEMINÁRIO DA REDESTRADO - REGULAÇÃO EDUCACIONAL E TRABALHO DOCENTE, 6., 2006, Rio de Janeiro. Anais eletrônicos... Disponível em: <http://www.fae.ufmg.br/estrado/cd_viseminario/trabalhos/eixo_tematico_1/ as_reformas_em_mg_choqeu_gestao.pdf>. Acesso em: 30 maio 2009.

BELLONI, M. L. O que é mídia-educação? Campinas: Autores Associados, 2001.

BORGES, M. de F. V. Inserção da informática em ambiente escolar: inclusão digital e laboratórios de informática numa rede municipal de ensino. 2007. $112 \mathrm{f}$. Dissertação (Mestrado em Educação Tecnológica) - Centro Federal de Educação Tecnológica de Minas Gerais, Belo Horizonte, 2007.

BRASIL. Ministério de Educação e do Desporto. Conselho Nacional de Educação / Conselho Pleno. Resolução CNE/CP 1, de 18 de fevereiro de 2002. Institui diretrizes curriculares nacionais para a formação de professores da educação básica, em nível superior, curso de licenciatura, de graduação plena. Brasília, DF, 18 fev. 2002. Disponível em: <http://portal.mec.gov.br/cne/arquivos/pdf/rcp01_02. pdf>. Acesso em: 15 jul. 2009.

BRIGHENTI, M. J. L.; BARROS, D. M. V. Tecnologia da informação e comunicação \& formação de professores: tecendo algumas redes de conexão. In: RIVERO, C. M. da L.; GALLO, S. (Org.). Formação de professores na sociedade do conhecimento. Bauru: EDUSC, 2004, p. 125-144.

CANDAU, V. M. Magistério: construção cotidiana. Petrópolis: Vozes, 1997.

CORREIA, C. C.; BONIFÁCIO, R. S.; NUNES, L. C. O curso de capacitação de professores em informática educativa como possibilidade de mudança na prática docente. In: REUNIÃO ANUAL DA ASSOCIAÇÃO DE PÓS-GRADUAÇÃO E PESQUISA EM EDUCAÇÃO - ANPED, 26., 2007, Caxambu. Anais... Caxambu: ANPED, 2007. Disponível em: <www.anped.org.br/reunioes/30ra/ trabalhos/gt08-3083--res.pdf>. Acesso em: 4 mar. 2008.

FARIAS, I. M. S. de. Os professores e as tecnologias na escola: limites e perspectivas da inovação. Tecnologia educacional, v. 30/31, n. 159/160, p. 11-20, 2002/2003. 
GATTI, B. A. Análise das políticas públicas de formação continuada no Brasil, na última década. Revista Brasileira de Educação, v. 13, n. 37, p. 57-69, 2008.

KENSKI, V. M. Tecnologias e ensino presencial e a distância. Campinas: Papirus, 2003.

MELO, M. T. L. Programas oficiais para formação dos professores da Educação Básica. Educação e Sociedade, v. 20, n. 68, p. 45-60, 1999.

NASCIMENTO, M. G. A formação continuada dos professores: modelos, dimensões e problemática. In: CANDAU, V. M. Magistério: construção cotidiana. 5. ed. Petrópolis: Vozes, 1997. p. 69-90.

PAGNEZ, K. S. M. M. Projeto Eureka: a implantação da informática educativa na rede municipal de campinas no período de 1989-1997. Ensaio: Avaliação de Políticas Públicas em Educação, v. 14, n. 51, p. 249-260, 2006.

STAHL, M. Formação de professores para o uso das novas tecnologias da informação e comunicação. In: CANDAU, V. M. Magistério: construção cotidiana. 5. ed. Petrópolis: Vozes, 2003.

VALENTE, J. A. A telepresença na formação de professores na área de informática em educação: implantando o construcionismo contextualizado. In: CONGRESSO IBERO-AMERICANO DE INFORMÁTICA NA EDUCAÇÃO, 4., 1998, Brasília. Anais eletrônicos... Brasília: Congresso Ibero Americano de Informática na Educação, 1998. Disponível em: <http://ism.dei.uc.pt/ribie/docfiles/ txt200342421644232-pdf>. Acesso em: 30 maio de 2009.

VOSGERAU, D. S. R et al. Análise de diferentes propostas para avaliação da integração dos recursos tecnológicos na prática pedagógica do professor: ampliando as ações do Projeto Cri@tividade. In: ENCONTRO NACIONAL DE DIDÁTICA E PRÁTICA DE ENSINO, 15., 2010, Belo Horizonte. Anais eletrônicos... Belo Horizonte: ENDIPE, 2010. p. 2-12.

Recebido: 16/04/2010

Received: 04/16/2010

Aprovado: 21/06/2010

Approved: 06/21/2010 